\title{
Four Members of Heat Shock Protein 70 Family in Korean Rose Bitterling (Rhodeus uyekii)
}

\author{
Jung Hyun Kim ${ }^{1}$, Chun Mae Dong ${ }^{1}$, Julan Kim ${ }^{1}$, Cheul Min An ${ }^{1}$, Hae Ja Baek ${ }^{2}$ and ${ }^{\dagger}$ Hee Jeong Kong ${ }^{1}$ \\ ${ }^{1}$ Biotechnology Research Division, National Fisheries Research and Development Institute, Busan 46083, Korea \\ ${ }^{2}$ Dept. of Marine Biology, Graduate School, Pukyong National University, Busan 48513, Korea
}

\begin{abstract}
Heat shock protein (HSP) 70, the highly conserved stress protein families, plays important roles in protecting cells against heat and other stresses in most animal species. In the present study, we identified and characterized four Hsp70 (RuHSP4, RuHSC70, RuHSP12A, RuGRP78) family proteins based on the expressed sequence tag (EST) analysis of the Korean rose bitterling $R$. uyekii cDNA library. The deduced RuHSP70 family has high amino acid identities of 72-99\% with those of other species. Phylogenetic analysis revealed that RuHsp70 family clustered with fish groups (HSP4, HSC70, HSP12A, GRP78) proteins. Quantitative RT-PCR analysis showed the specific expression patterns of RuHsp70 family members in the early developmental stages and several tissues in Korean rose bitterling. The expression of 4 groups of Hsp70 family was detected in all tested tissue. Particularly, Hsp70 family of Korean rose bitterling is highly expressed in hepatopancreas and sexual gonad (testis and ovary). The expression of Hsp70 family was differentially regulated in accordance with early development stage of Rhodeus uyekii.
\end{abstract}

Key words : Development, Expression, Korean rose bitterling, HSP 70 family, Rhodeus uyekii

\section{INTRODUCTION}

The heat shock or stress response refers to the reaction of cellular organisms to adverse environmental stresses such as heat stress and heavy metals, which are highly conserved proteins (Welch et al., 1991). It composed of the rapid and coordinated induction of a group of proteins referred to as the stress proteins and the concomitant reduction of normal cellular proteins. The stress proteins can be divided into two groups of families: the heat shock proteins (HSPs) and the glucose-regulated proteins (GRPs). HSPs are categorized into several families and named according to their function, sequence homology and molecular mass in kilo-Daltons
(kDa): HSP100, HSP90, HSP70, HSP60, HSP40 and several smaller HSP groups (Lindquist, 1992).

HSP70 is the largest and most highly conserved of the stress protein families (Sanders, 1993). HSP70 family contains four major members: HSP70, heat shock cognate 70 (Hsc70), HSP75 and GRP78 (Polanowska-Grabowska et al., 1997; Bausero et al., 2005). At least 121 proteins have been isolated in the HSP70 family and cross-hybridization occurs across mammals, fish and molluscs; indeed, humans and molluses share the same antigenic and ATP binding domains (Margulis et al., 1989; Roberts et al., 2010). Hsp70 family was isolated from a variety of fishes such as rainbow trout (Kothary et al., 1984), Oryzias latipes (Arai et al., 1995), Zebrafish

\footnotetext{
Manuscript received 17 June 2015, Received in revised form 25 June 2015, Accepted 7 July 2015

${ }^{\dagger}$ Corresponding Author : Hee Jeong Kong, Biotechnology Research Division, National Fisheries Research and Development Institute (NFRDI), 216 Haean-ro, Gijang-up, Gijang-gun, Busan 46083, Republic of Korea. Tel. : +82-51-720-2453, Fax :+82-51-720-2456, E-mail : heejkong@korea.kr

This is an Open Access article distributed under the terms of the Creative Commons Attribution Non-Commercial License (http:// creativecommons.org/licenses/by-nc/3.0) which permits unrestricted non-commercial use, distribution, and reproduction in any medium, provided the original work is properly cited.
} 
(Lele et al., 1997), Oreochromis mossambicus (Molina et al., 2000) and Fugu rubripes (Lim \& Brenner, 1999) etc. Hsp70 family also has been reported to be associated with differences in environmental temperatures (Feder \& Hofmann, 1999).

Most of the HSPs are also constitutively synthesized in considerable amounts even in the unstressed normal cells (Welch et al., 1991; Roberts et al., 2010; Hunt \& Morimoto, 1985), which play a fundamental role in the regulation of normal protein synthesis within the cell. HSP families such as HSP90 and HSP70 are critical to the folding and assembly of other cellular proteins (Gething \& Sambrook, 1992). These also have a wider role in relation to the immune, apoptotic and inflammatory processes (Moseley, 2000; Srivastava, 2002; Pockley, 2003). Depletion of either HSP70 or HSP90 in a transgenic zebrafish model caused defects in blood vessel formation through the modulation of VEGF-A-stimulated intracellular signaling, endothelial cell migration, blood vessel development and repair (Bruns et al., 2012).

In this study, we report the identification and molecular characterization of the Korean rose bitterling (Rhodeus uyekii) HSP70 family members. We analyzed multiple alignments and phylogenetic tree of the deduced RuHSP70 family sequences and other homologs. We investigated the expression of RuHSP70 transcript during early development and in several tissues of Korean rose bitterling. This is the first report of molecular and functional analyses of the Korean rose bitterling HSP70 gene.

\section{MATERIALS AND METHODS}

\section{Fish maintenance and sample preparation}

Rhodeus uyekii were collected from the Yangchun River, Uiryung-gun, Gyungnam, Republic of Korea. The fish were maintained at the National Fisheries Research and Development Institute (NFRDI) in Busan, Republic of Korea (Kim et al., 2014). The adults were maintained in $40 \mathrm{~L}$ glass aquaria at a density of approximately 20 fish per aquarium. The water was renewed weekly and the temperature in the rearing tanks was maintained at $20 \pm 1{ }^{\circ} \mathrm{C}$. The room was maintained on a 12:12-h light:dark cycle. Adults were fed TetraBits (Tetra) and frozen bloodworms (Advanced Hatchery Technology) twice a day. For RNA extraction, the sample of 10 randomly selected embryo or fish were collected and immediately frozen in liquid nitrogen, and stored at $-80^{\circ} \mathrm{C}$ before use.

\section{Identification of Korean rose bittering $R$. uyekii} RuHSP70 family

The RuHSP70 family cDNA sequences were isolated from the expressed sequence tag (EST) analysis of the Korean rose bittering $R$. uyekii cDNA library. EST clones were isolated using a Plasmid Miniprep Kit (Qiagen), and sequenced using T3 reverse primers (Promega) and an ABI3730xl automatic sequencer (Applied Biosystems). The nucleotide sequence was analyzed and compared using the BLASTX search program (http://www.ncbilnlm.nih.gov/ BLAST/).

\section{Multiple sequence alignment and phylogenetic} analysis

The relevant sequences were compared using the BLASTX search program (http://www.ncbi.nlm.nih.gov/BLAST/) and retrieved from GenBank for multiple sequence alignments using CLUSTALW (http://www.genome.jp/tools-bin/clustalw). MEGA (ver. 4) was used to assess homologies among the aligned sequences. A phylogenetic tree based on the deduced amino acid sequences was constructed using a neighborjoining algorithm, and the reliability of the branching was tested using bootstrap resampling with 1,000 pseudo-replicates.

\section{Quantitative real-time PCR}

Total RNA was prepared from tissues using TRIzol reagent (Invitrogen, Carlsbad, CA, USA) according to the manufacturer's instructions, treated with DNase I (New England BioLabs, Beverly, MA, USA) and quantitatively 
Table 1. Sequences of primers used for the RT-PCR

\begin{tabular}{cccc}
\hline \hline Gene & Primer & Sequence $\left(5^{\prime} \rightarrow 3^{\prime}\right)$ & Amplicon length(bp) \\
\hline \multirow{2}{*}{ RuHSP4 } & Forward & CCT GGC AGG GCG TTC A & 74 \\
& Reverse & GGCATCTGAGCA AGATCA AAG A & 82 \\
\hline \multirow{2}{*}{ RuHSC70 } & Forward & GGATGACGTCCA AAG AGA AAAGG & 74 \\
& Reverse & ATCTTCAACGGTGGACTTCATGT & 74 \\
\hline \multirow{2}{*}{ RuHSP12A } & Forward & AGCGTATAAGGCTGGTCTGGTT & 74 \\
& Reverse & ATGCAGCTTCTGGTTCCAAAG & \\
\hline \multirow{2}{*}{ RuGRP78 } & Forward & CCACCAGAGTGAAGGGAAAAAA & \\
& Reverse & CGTGAAGCCACGAGGAAAGA & \\
\hline
\end{tabular}

determined; $500 \mathrm{ng}$ samples were used for reverse transctiption (RT). First-strand cDNA was synthesized using Transcriptor First Strand cDNA Synthesis Kit (Roche). Quantitative real-time PCR was performed using Fast SYBR Green Master Mix (Applied Biosystems, Inc.). The PCR primers used for real-time PCR are listed in Table 1. Following an initial 10 -min Taq activation step at $95^{\circ} \mathrm{C}$, real-time PCR was performed using the following cycling conditions: 40 cycles of $95^{\circ} \mathrm{C}$ for $10 \mathrm{~s}, 60^{\circ} \mathrm{C}$ for $15 \mathrm{~s}$, and fluorescence reading in an SDS 7500 system (Applied Biosystems, Inc.). Transcript levels were quantified as expression relative to the $\beta$-actin transcript level.

\section{RESULTS AND DISCUSSION}

\section{Identification of four Hsp70 family cDNA sequences} in the Korean rose bittering

The partial sequences of Korean rose bittering Hsp70 family were identified from the expressed sequence tag (EST) analysis of the R. uyekii cDNA library. A search using the BLASTX program (http://www.ncbi.nlm.nih.gov/ blast/Blast.cgi) and pairwise alignment revealed that the deduced amino acids of EST clones RU-1-2a_I02, RU-13a_F01, RU-2-1a_I11 and RU-2-3a_F17 showed the high homology with heat shock protein $70 \mathrm{kDa}$ 4-like (HSP4), heat shock cognate 70 (HSC70), heat shock protein $70 \mathrm{kDa}$ 12A-like (HSP12A) and glucose regulated protein 78 (GRP78) of other species, respectively. Accession no. XM008284359.1, AY538777.1, NM001045435.1 and N595368.1.

2. Comparison of RuHSP70 family with other homologs

The deduced amino acids of RuHSP70 family were aligned with Hsp70 proteins from other species including Tongue sole, biocolor damselfish, Zebrafish, Amazon molly, Korean rose bittering, Cichlidae, Asiatic ricefish, Prussian carp, Minnows, Grass carp, Channel catfish, Mexican tetra Zebra mbuna, Cichlid, guppy, Southern platyfish, Alpaca, Mouse, Human, Olive baboon, Cow, Hamster, Sheep, Falcon, Burmese python, Hill pigeon, African elephant (Fig. 1). Pairwise alignment revealed RuHSP70 family showed high amino acid identities of $72-99 \%$ with those of other species. In Table 2, RuHSP4 showed high homology with Stegastes parties and Poecilia formosa. RuHSC70 showed high homology with Carassius gibelio, Hypophthalmichthys molitrix and Pimephales promelas. RuHSP12A showed high homology with Danio rerio and Astyanax mexicanus. RuGRP78 showed high homology with Ctenopharyngodon idell and Danio rerio.

3. Phylogenetic analysis of RuHSP70 family with other homologs

A phylogenetic analysis, based on the deduced amino acid sequence of RuHSP70 family and related sequences, 
a

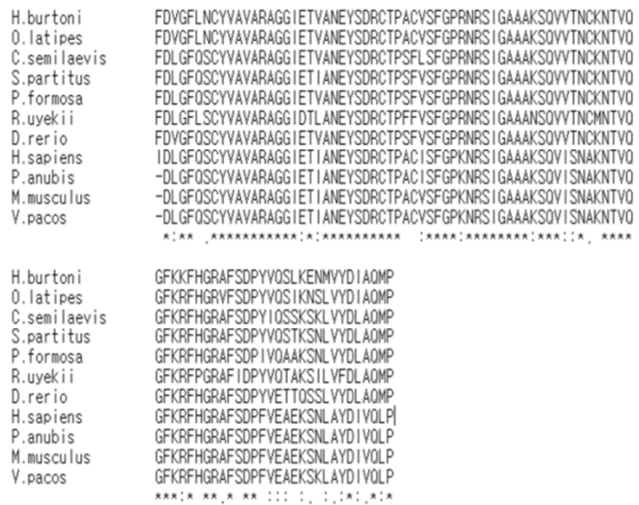

C

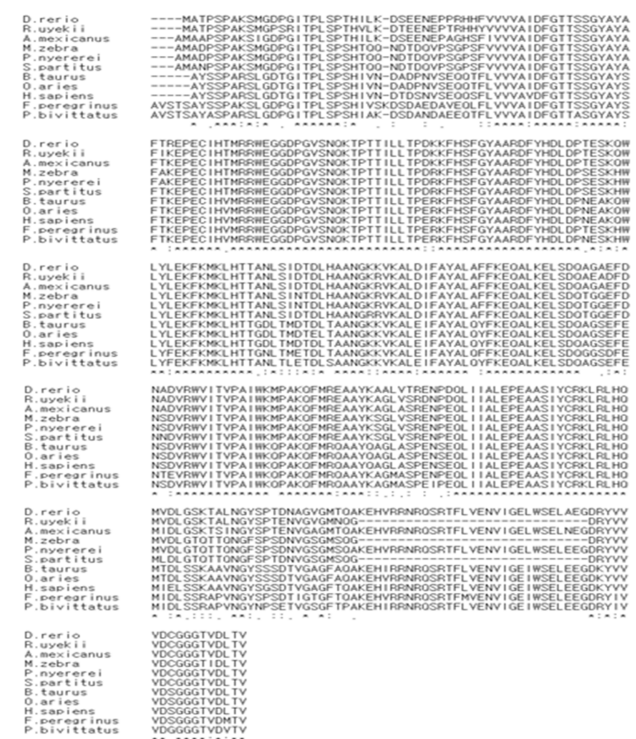

b

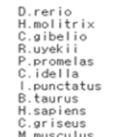

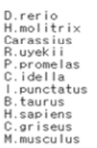

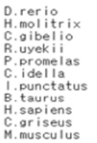

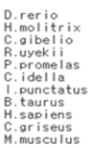

d
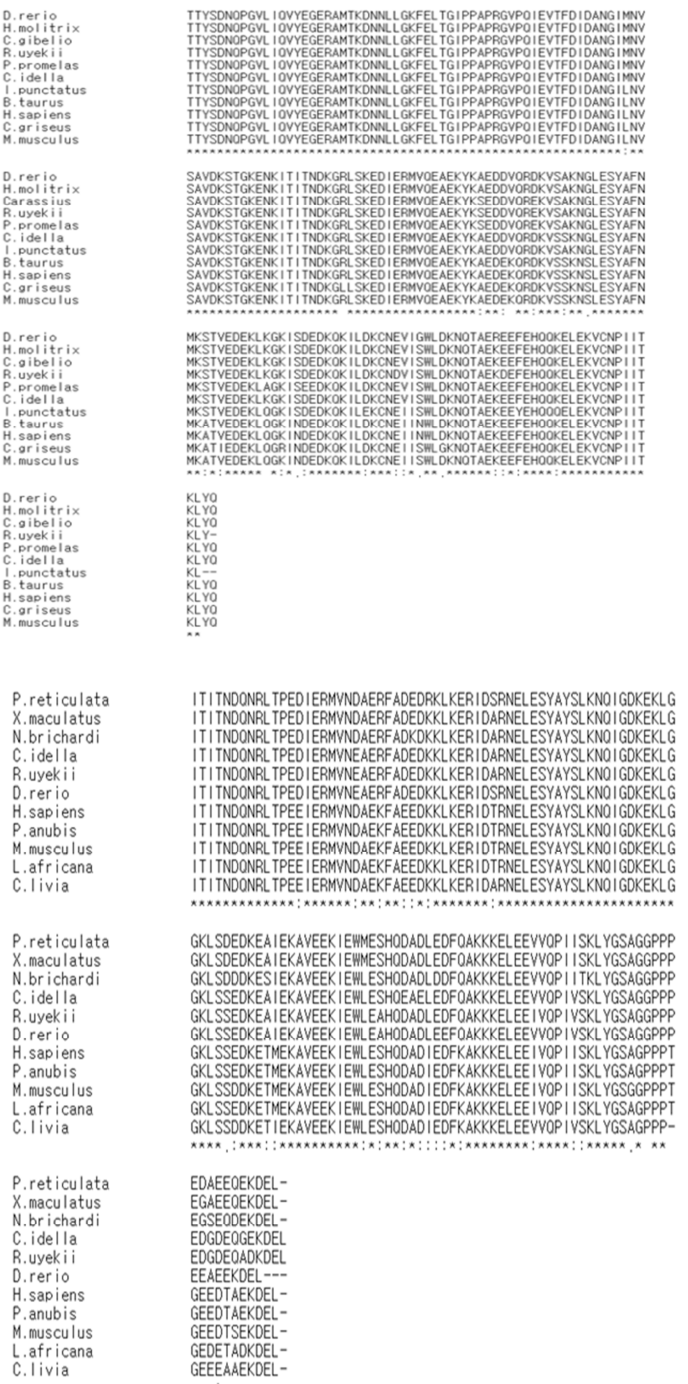

KLYO
KLY
KLY
KLY
KLY
KLY
KL
KLY
KLY
KLY
KLY
KLY

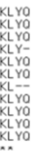

Fig. 1. Multiple alignment of the amino acid sequences of the Korean rose bitterling heat shock protein 70 family (RuHSP70 family) and related sequences. A multiple alignment of amino acid sequences of Hsp70 family was produced using ClustalW 1.81. GenBank accession numbers for the analyzed sequences are the following: (a) Haplochromis burtoni (XP-005921284), Oryzias latipes (XP-004073389), Cynoglossus semilaevis (XP008331072), Stegastes partitus (XP-008296412), Poecilia formosa (XP-007562090), Danio rerio (NP_999881), Homo sapiens (AAH02526), Papio anubis (XP-003900145), Mus musculus (EDL33602), Vicugna pacos (XP006212876). (b) Anio rerio (NP-001103873), Hypophthalmichthys moliteix (ACJ03595), Carassius gibelio (AAO43731), Pimephales promelas (AAS46619), Ctenopharyngodon idella (ACJ03596), Ictalurus punctatus (ABD77547), Bos taurus (AAI54390), Homo sapiens (AAH08907), Cricetulus griseus (EGW02963), Mus musculus (BAE29904). (c) Danio rerio (NP_001038900), Astyanax mexicanus (XP-007244701), Maylandia zebra (XP-004572562), Pundamilia nyererei (XP-005747498), Stegastes partitus (XP-008305029), Bos taurus (AAI54390), Ovis aries (XP-004020391), Homo sapiens (XP-005269729), Falco peregrinus (XP-005239629), Python bivittatus (XP007433493). (d) Poecilia retculata (XP-008422585), Xiphophorus maculatus (XP-005803813), Neolamprologus brichardi (XP-006789208), Ctenopharyngodon idella (ACJ65009), Danio rerio (AAH63946), Homo sapiens (EAW87621), Papio anubis (XP-003911999), Mus musculus (AAA37315), Loxodonta africana (XP-003407784), Columba livia (XP-005513063). Identical residues are indicated by asterisks $\left(^{*}\right)$; conservative substitutions are indicated by dots (.:). 
Table 2. Pairwise ClustalW analysis of the deduced amino acid sequences of RuHSP70 family with those of other species

\begin{tabular}{|c|c|c|}
\hline Species & GenBank no. & Identity $(\%)$ \\
\hline \multicolumn{3}{|l|}{ (A) RuHSP4 } \\
\hline Haplochromis burtoni Heat shock $70 \mathrm{kDa}$ protein 4-like & XP_005921284 & 80 \\
\hline Oryzias latipes Heat shock $70 \mathrm{kDa}$ protein 4-like & XP_004073389 & 81 \\
\hline Cynoglossus semilaevis Heat shock protein $105 \mathrm{kDa}$ isoform $\mathrm{X} 1$ & XP_008331072 & 84 \\
\hline Stegastes partitus Heat shock $70 \mathrm{kDa}$ protein 4 -like & XP_008296412 & 87 \\
\hline Poecilia formosa Heat shock $70 \mathrm{kDa}$ protein 4-like & XP_007562090 & 87 \\
\hline Danio rerio Heat shock protein $4 \mathrm{a}$ & NP_999881 & 84 \\
\hline Homo sapiens Heat shock 70kDa protein 4 & AAH02526 & 72 \\
\hline Papio anubis Heat shock $70 \mathrm{kDa}$ protein 4 & XP_003900145 & 73 \\
\hline Mus musculus Heat shock protein 4, isoform CRA_b & EDL33602 & 74 \\
\hline Vicugna pacos Heat shock $70 \mathrm{kDa}$ protein 4 isoform $\mathrm{X} 2$ & XP_006212876 & 74 \\
\hline \multicolumn{3}{|l|}{ (B) RuHSC70 } \\
\hline Danio rerio Heat shock cognate $71 \mathrm{kDa}$ protein & NP_001103873 & 97 \\
\hline Hypophthalmichthys molitrix Heat shock protein 70 & ACJ03595 & 98 \\
\hline Carassius gibelio Heat shock cognate $70 \mathrm{kDa}$ protein & AAO43731 & 99 \\
\hline Pimephales promelas Heat shock cognate $70 \mathrm{kDa}$ protein & AAS46619 & 98 \\
\hline Ctenopharyngodon idella Heat shock protein 70 & ACJ03596 & 97 \\
\hline Ictalurus punctatus Heat shock cognate $70 \mathrm{kDa}$ protein & ABD77547 & 95 \\
\hline Bos taurus HSPA8 protein & AAI54390 & 92 \\
\hline Homo sapiens HSPA8 protein & AAH08907 & 92 \\
\hline Cricetulus griseus Heat shock cognate $71 \mathrm{kDa}$ protein & EGW02963 & 91 \\
\hline Mus musculus Unnamed protein product & BAE29904 & 95 \\
\hline
\end{tabular}

(C) RuHSP12A

Danio rerio Heat shock protein $12 \mathrm{~A}$

NP_001038900 92

Astyanax mexicanus Heat shock $70 \mathrm{kDa}$ protein $12 \mathrm{~A}$ isoform $\mathrm{X} 1$

XP_007244701 91

Maylandia zebra Heat shock $70 \mathrm{kDa}$ protein 12A-like isoform X4

XP_004572562 85

Pundamilia nyererei Heat shock $70 \mathrm{kDa}$ protein 12A-like isoform X5

XP_005747498 84

Stegastes partitus Heat shock $70 \mathrm{kDa}$ protein 12A isoform X3

XP_008305029 85

Bos taurus Heat shock $70 \mathrm{kDa}$ protein 12A isoform X1

XP_002698580 76

Ovis aries Heat shock $70 \mathrm{kDa}$ protein 12A

Homo sapiens Heat shock $70 \mathrm{kDa}$ protein $12 \mathrm{~A}$ isoform $\mathrm{X} 1$

XP_004020391 75

Falco peregrinus Heat shock $70 \mathrm{kDa}$ protein $12 \mathrm{~A}$

XP_005269729 75

Python bivittatus Heat shock $70 \mathrm{kDa}$ protein 12A-like isoform X1

XP_005237627 74

XP_007433493 74 


\begin{tabular}{lcc}
\hline \hline \multicolumn{1}{c}{ Species } & GenBank no. & Identity(\%) \\
\hline (D) RuGRP78 & & \\
Poecilia reticulata 78 kDa glucose-regulated protein & XP_008422585 & 89 \\
Xiphophorus maculatus 78 kDa glucose-regulated protein-like & XP_005803813 & 90 \\
Neolamprologus brichardi 78 kDa glucose-regulated protein-like & XP_006789208 & 88 \\
Ctenopharyngodon idella GRP78 & ACJ65009 & 95 \\
Danio rerio Heat shock protein 5 & AAH63946 & 93 \\
Homo sapiens Heat shock 70kDa protein 5 & EAW87621 & 84 \\
Papio anubis 78 kDa glucose-regulated protein-like & XP_003911999 & 84 \\
Mus musculus Immunoglobulin heavy chain binding protein & AAA37315 & 82 \\
Loxodonta africana 78 kDa glucose-regulated protein & XP_003407784 & 86 \\
Columba livia 78 kDa glucose-regulated protein & XP_005513063 & 86 \\
\hline
\end{tabular}

was performed. RuHSP70 family was divided into two distinct groups, one as fisheries and the other one as mammals. The tree indicated clear clustering of RuHSP4 sequences into two groups: Amazon molly; Bicolor damselfish; Tongue sole; Zebrafish; Cichlidae; Asiatic ricefish VS alpaca; mouse; olive baboon and human. The tree indicated clear clustering of RuHSC70 sequences into two groups: Prussian carp; Minnows; Zebrafish; Cuvier et valenciennes; Grass carp; Channel catfish VS Cow; Human; Hamster and Mouse. The tree indicated clear clustering of RuHSP12A family sequences into two groups: Zebrafish; Mexican tetra; Bicolor damselfish; Zebra mbuna; Cichlid VS Falcon; Burmese python; Human; Cow and Sheep. The tree indicated clear clustering of RuGRP78 sequences into two groups: Grass carp; Zebrafish; Guppy; Southern platyfish VS Hill pigeon; African elephant; mouse; olive baboon and human (Fig. 2).

\section{Tissue distribution of Hsp70 family mRNA in Korean rose bitterling}

Tissue distribution of Hsp70 family mRNA in Korean rose bitterling were investigated by quantitative real-time
PCR. The expression levels of Hsp70 family mRNA were quantified after normalization to $\beta$-actin as an internal reference gene. The expression of RuHSP4 mRNA was detected in all tissue examined; highly in the ovary, testis and hepatopancreas. Levels of the RuHSP4 mRNA in the ovary, testis and hepatopancreas were 14.6, 11.3 and 9.8 folds that in gill where expression was the lowest, respectively. The expression of RuHSC70 mRNA was detected in all tissue examined; highly in the hepatopancreas, testis and spleen. Levels of the RuHSC70 mRNA in the hepatopancreas, testis and spleen were 2.7, 1.8 and 1.1 folds that in muscle where expression was the lowest, respectively. The expression of RuHSP12A mRNA was detected in all tissue examined; highly in the ovary, testis and brain. Levels of the RuHSP12A mRNA in the ovary, testis and brain were 2.8, 1.1 and 1 folds that in gill where expression was the lowest, respectively. The expression of RuGRP78 mRNA was detected in all tissue examined; highly in the hepatopancreas, spleen and ovary. Levels of the RuGRP78 mRNA in the hepatopancreas, spleen and ovary were $42.1,28.2$ and 12.7 folds that in fin where expression was the lowest, respectively (Fig. 3). Overall, 

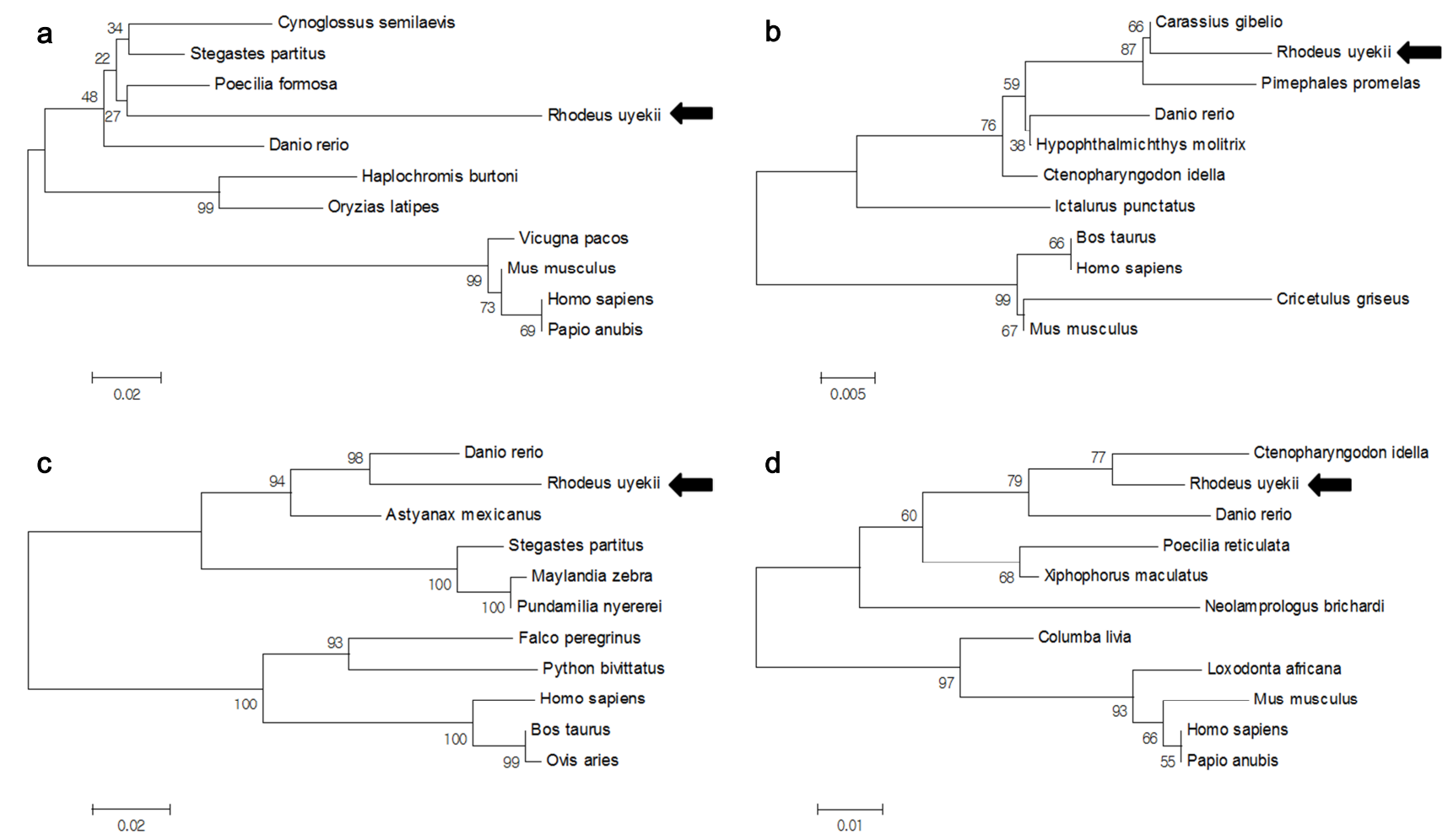

Fig. 2. Phylogenetic analysis of the Korean rose bitterling Hsp70 family and related sequences. GenBank accession numbers for the analyzed sequences are the following: (a) Haplochromis burtoni (XP-005921284), Oryzias latipes (XP-004073389), Cynoglossus semilaevis (XP-008331072), Stegastes partitus (XP-008296412), Poecilia formosa (XP007562090), Danio rerio (NP-999881), Homo sapiens (AAH02526), Papio anubis (XP-003900145), Mus musculus (EDL33602), Vicugna pacos (XP-006212876). (b) Danio rerio (NP-001103873), Hypophthalmichthys molitrix (ACJ03595), Carassius gibelio (AAO43731), Pimephales promelas (AAS46619), Ctenopharyngodon idella (ACJ03596), Ictalurus punctatus (ABD77247), Bos taurus (AAI54390), Homo sapiens (AAH08907), Cricetulus griseus (EGW02963), Mus musculus (BAE29904). (c) Danio rerio (NP-00038900), Astyanax mexicanus (XP-007244701), Maylandia zebra (XP-004572562), Pundamilia nyererei (XP-005747498), Stegastes partitus (XP-008305029), Bos taurus (XP-002698580), Ovis aries (XP-004020391), Homo sapiens (XP-005269729), Falco peregrinus (XP-005237627), Python bivittatus (XP-007433493). (d) Poecilia reticulate (XP-008422585), Xiphophorus maculatus (XP-005803812), Neolamprologus brichardi (XP-006789208), Ctenopharyngodon idella (ACJ65009), Danio rerio (AAH63946), Homo sapiens (EAW87621), Papio anubis (XP-003911999), Mus musculus (AAA37315), Loxodonta africana (XP-003407784), Columba livia (XP-005513063).

we found that Hsp70 family of Korean rose bitterling is highly expressed in hepatopancreas and sexual gonad (testis, ovary). This expression pattern is consistent with high previous results. The results showed that Hap 70 family was highly expressed in hepatopancreas and sexual gonad (testis, ovary) in Rhynchocypris kumgangensis (Im et al., 2013) and Paphia undiata (Wu et al., 2014).
5. Expression analysis of the HSP70 family mRNA during early development

The expression of Hsp70 family mRNA during early development of Korean rose bitterling was determined by quantitative real-time PCR at 1, 3, 6, 15 and 21 days postfertilization (dpf). After the first dpf, the relative expression of RuHSP4 sharply decreased and was maintained at similar 
(A)

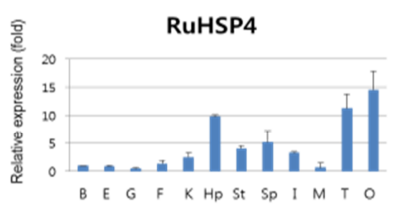

(C)

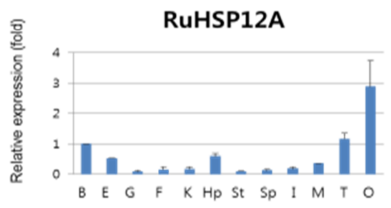

(B)

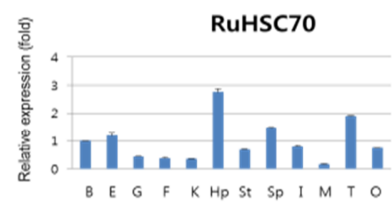

(D)

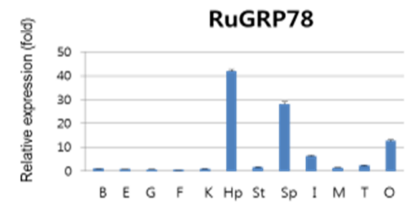

Fig. 3. Tissue distribution of The Korean rose bitterling

RuHSP70 family. Quantitative real-time RT-PCR was performed on equal amounts of total RNA isolated from tissues of normal conditioned fish. Korean rose bitterling $\beta$-actin was used as an internal control. Expression levels of (A) RuHSP4, (B) RuHSC70, (C) RuHSP12A, (D) RuGRP78 transcript were quantified by expression relative to the $\beta$-actin transcript level. B, brain; E, eye; G, gill; F, fin; K, kidney; Hp, hepatopancreas; St, stomach; Sp, spleen; $\mathrm{I}$, intestine; $\mathrm{M}$, muscle; $\mathrm{T}$, testis; $\mathrm{O}$, ovary. The values represent the mean $\pm \mathrm{SD}(\mathrm{n}=3)$.

level, until the last dpf. The expression of RuHSC70 mRNA was detected from $1 \mathrm{dpf}$ and moderately increased until $21 \mathrm{dpf}$ during the early development. The relative expression of RuHSP12A and RuGRP78 increased significantly at the $15 \mathrm{dpf}$ and decreased slightly at $21 \mathrm{dpf}$ (Fig. 4).

The results of previous research are similar to our study. It is consistent that the expression of Hsp70 family gene was increased after fertilization in Oncorhynchus tshawytscha (Kong et al., 1996), Oncorhynchus mykiss (Currie \& Tufts., 1997; Currie et al., 2000; Ojima et al., 2005a, b) and Salmo salar (Lund et al., 2002). We expected that differences in the expression are due to differences on the role of Hsp70 family mRNA at various stage of development. Further investigations are required to determine the function of Hsp70 family in development stage of Korean rose bitterling under in vivo and vitro conditions.
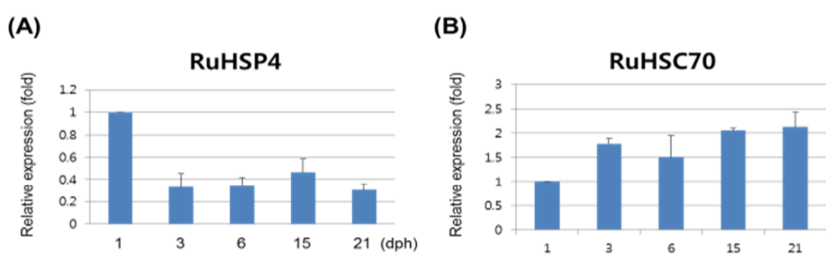

(C)
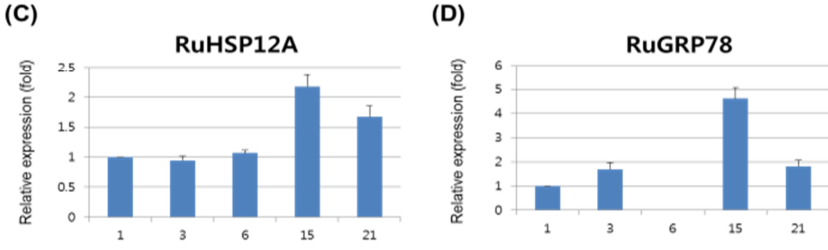

Fig. 4. Development stage of the Korean rose bitterling RuHSP70 family. Quantitative real-time RT-PCR was performed on equal amounts of total RNA isolated from during development stage of whole body in fish. Korean rose bitterling $\beta$-actin was used as an internal control. Expression levels of (A) RuHSP4, (B) RuHSC70, (C) RuHSP12A, (D) RuGRP78 transcript were quantified by expression relative to the $\beta$-actin transcript lever. The values represent the mean $\pm \mathrm{SD}(\mathrm{n}=3)$.

In this study, the partial sequences of Korean rose bittering Hsp70 family were identified from the expressed sequence tag (EST) analysis of the $R$. uyekii cDNA library. We found 4 members (RuHSP4, RuHSC70, RuHSP12A, RuGRP78) of Hsp70 family in R. uyekii. Pairwise alignment and phylogenetic analysis revealed RuHSP70 family showed RuHsp70 family has been conserved during evolution. The expression patterns of RuHsp70 family suggest that they play a unique or specific role during early development. Further investigations are required to elucidate the functional role of HSP70 families in $R$. uyekii.

\section{ACKNOWLEDGEMENTS}

This work was supported by a grant from the National Fisheries Research and Development Institute (NFRDI), Republic of Korea (R2015023). 


\section{REFERENCES}

Arai A, Naruse K, Mitani H, Shima A (1995) Cloning and characterization of cDNAs for 70-kDa heat-shock proteins (Hsp70) from two fish species of the genus oryzias. Jpn J Genet 70:423-433.

Bausero MA, Gastpar R, Multhoff G, Asea A (2005) Alternative mechanism by which IFN- $\gamma$ enhances tumor recognition: Active release of heat shock protein 72 . J Immunol 175:2900-2912.

Bruns AF, Yuldasheva N, Latham AM, Bao L, Pellet-Many C, Frankel P (2012) A heat-shock protein axis regulates VEGFR2 proteolysis, blood vessel development and repair. PLoS ONE 7:e48539.

Currie S, Moyes CD, Tufts BL (2000) The effects of heat shock and acclimation temperature on heat shock protein 70 and heat shock protein 30 mRNA expression in rainbow trout: in vivo and in vitro comparisons. J Fish Biol 56:398-408.

Currie S, Tufts BL (1997) Synthesis of stress protein 70 (Hsp70) in rainbow trout (Oncorhynchus mykiss) red blood cells. J Exp Biol 200:607-614.

Feder ME, Hofmann GE (1999) Heat-shock proteins, molecular chaperones, and the stress response: Evolutionary and ecological physiology. Annual Reviews Physiology 61:243-282.

Gething MJ, Sambrook J (1992) Protein folding in the cell. Nature 355:33-45.

Hunt C, Morimoto RI (1985) Conserved features of eukaryotic HSP70 genes revealed by comparison with the nucleotide sequence of human HSP70. Proc Natl Acad Sci USA 82:6455-6459.

Im JS, Ghil SH (2013) Cloning of heat shock protein 70 and its expression profile under an increase of water temperature in Rhynchocypris kumgangensis. J Korean Society on Water Environment 29:232-238.

Kim JL, Kong HJ, Kim HS, Kim WJ, Kim DG, Nam BH,
Kim YO, An CM (2014) Fish myogenic regulatory protein LUC71: Characterization and expression analysis in Korean rose bitterling (Rhodeus uyekii). Dev Reprod $18: 251-258$.

Kong HJ, Kang HS, Kim HD (1996) Expression of the heat shock proteins in HeLa and fish CHSE-214 cell exposed to heat shcok. Korean J Zool 39:123-131.

Kothary PK, Burgess EA, Candido EPM (1984) The heatshock phenomenon in cultured cells of rainbow trout: hsp70 mRNA synthesis and turnover. Biochim Biophys Acta 783:137-143.

Lele Z, Engel S, Krone PH (1997) Hsp47 and Hsp70 gene expression is differentially regulated in a stress- and tissue-specific manner in zebra-fish embryos. Dev Genet 21:123-133.

Lim EH, Brenner S (1999) Short-range linkage relationships, genomic organization and sequence comparisons of a cluster of five hsp70 genes in Fugu rubipes. Cell Mol Life Sic 55:668-678.

Lindquist S (1992) Heat-shock proteins and stress tolerance in microorganisms. Curr Opin Genet Dev 2:748-755.

Lund SG, Caissie D, Cunjak RA, Vijayan MM, Tufts BL (2002) The effects of environmental heat stress on heat shock mRNA and protein expression in Miramachi Atlantic Salmon (Salmo salar) parr. Can J Fish Aquat Sci 59:1553-1562.

Margulis BA, Antropova OY, Kharazova AD (1989) 70 $\mathrm{kDa}$ heat shock proteins from mollusc and human cells have common structural and functional domains. Comp Biochem Physiol 94b:621-623.

Molina A, Biemar F, Muller F, Iyengar A, Prunet P, Maclean N, Martial JA, Muller M (2000) Cloning and expression analysis of an inducible HSP70 gene from tilapia fish. FEBS Letters 474:5-10.

Moseley P (2000) Stress proteins and the immune response. Immunopharmacology 48:299-302.

Ojima N, Yamashita M, Watabe S (2005a) Comparative 
expression anlysis of two paralogous Hsp70s in rainbow trout cells exposed to heat stress. Biochem Biophys Res Commun 1681:99-106.

Ojima N, Yamashita M, Watabe S (2005b) Quantitative mRNA expression profiling of heat-shock protein families in rainbow trout cells. Biochem Biophys Res Commun 329:51-57.

Pockley AG (2003) Heat shock proteins as regulators of the immune response. Lancet 362:469-476.

Polanowska Grabowska R, Simon Jr Carl G, Falchetto R, Shabanowitz J, Hunt Donald F, Gear Adrian RL (1997) Platelet adhesion to collagen under flow causes dissociation of a phosphoprotein complex of heat-shock proteins and protein phosphatase 1. Blood 90:1516-1526.

Roberts RJ, Agius C, Saliba C, Bossier P, Sung YY (2010)
Heat chock proteins (chaperones) in fish and shellfish and their potential role in relation to fish health: a review. J Fish Dis 33:789-801.

Sanders BM, Martin LS (1993) Stress proteins as biomarkers of contaminant exposure in archived environmental samples. The Science of the Total Environment 139:459-470.

Srivastava P (2002) Roles of heat-shock proteins in innate and adaptive immunity. Nat Rev Immunol 2:185-194.

Welch WJ (1991) The role of heat shock proteins as molecular chaperones. Curr Opin Cell Biol 3:1033-1038.

Wu X, Tan J, Cai M, Liu X (2014) Molecular cloning, characterization, and expression analysis of a heat shock protein (HSP) 70 gene from Paphia undulata. Gene 543:275-285. 